\title{
Publisher Correction: Emergence of highly transparent photovoltaics for distributed applications
}

Christopher J. Traverse, Richa Pandey, Miles C. Barr and Richard R. Lunt

Correction to: Nature Energy https://doi.org/10.1038/s41560-017-0016-9 (2017); published online 23 October 2017

In the version of this Review originally published, the Fig. $7 \mathrm{a} y$-axis unit was incorrectly given as ' $\mathrm{mW} \mathrm{cm}^{2}$; it should have read ' $\mathrm{mW} \mathrm{cm}^{-2}$ '. This has now been corrected in all versions of the Review.

Published online: 29 January 2018

https://doi.org/10.1038/s41560-017-0069-9 